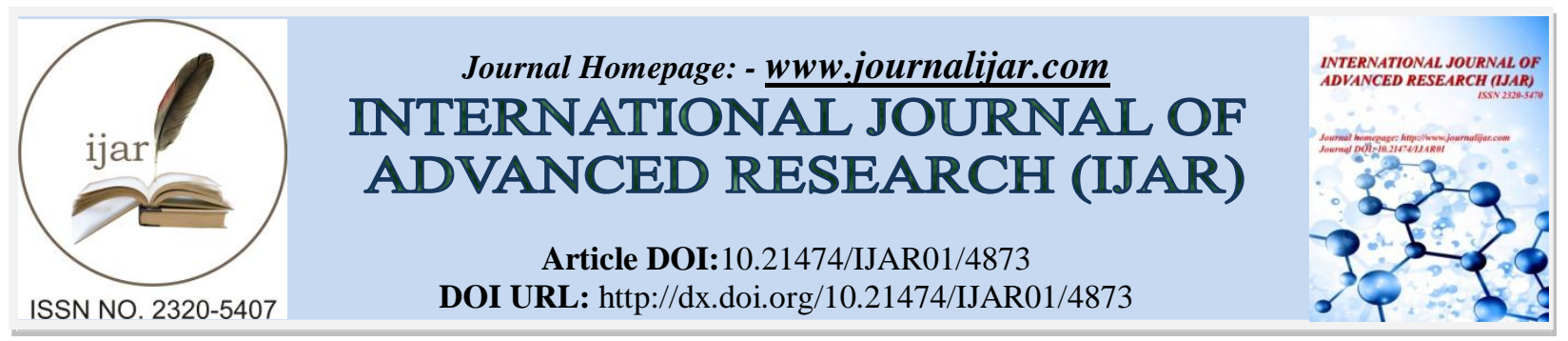

RESEARCH ARTICLE

\title{
UNDERSTANDING THE INDIAN TRIBAL LIFE AND THEIR ISSUES.
}

Purshottam $^{1}$ and Dr. Vanita Dhingra ${ }^{2}$.

1. PhD Research Scholar, Department of Social Work, Kurukshetra University, Kurukshetra, Haryana 136119.

2. Assistant Professor, Department of Social Work, Kurukshetra University, Kurukshetra, Haryana 136119.

\section{Manuscript Info}

\section{Manuscript History}

Received: 17 May 2017

Final Accepted: 19 June 2017

Published: July 2017

Key words:-

Tribal life, Indian tribes, health, education, understanding tribes, tribal issues, India.

\section{Abstract}

Tribal community in India has been the most vulnerable community. Their fundamental human rights are violated in every step of life. Tribals are backward and poor, living in naturally isolated regional inhabitant. Tribals in remote areas are still devoid of common infrastructure facilities of road and communication, health and education and safe drinking water and sanitation, which do not allow them to absorb technological and financial help provided by government. Scheduled tribes are indications of primitive traits, distinctive culture, geographical isolation, shyness of contact with the community at large, and backwardness. The tribal population of the country is 10.43 crore, constituting $8.61 \%$ of the total population. Madhya Pradesh has the largest number of ST's contributing 14.69\% to the total percentage of ST population of India.The paper tries to understand the different aspects of Indian tribal life, like distribution of tribes in India, history of tribes, etc. The paper highlighted the major issues like, social, religious, educational, health related problems and many more. The researcher also recommended some suggestions regarding the issues or challenges of tribes.

Copy Right, IJAR, 2017,. All rights reserved.

\section{Introduction:-}

The word "tribal" or Adivasi brings to our mind a picture of half-naked men and women, with arrows and spears in their hands, feathers in their heads, and speaking an unintelligible language. Even when majority of the communities in the world kept changing their life-styles very quickly to keep pace with the "progress" of the world, there were communities still living in line with their traditional values, customs and beliefs, where they could continue to live in peace with Nature and their unpolluted environment. The mainstream world, so called civilized people branded these communities variously as natives, uncivilized people, Aboriginals, Adivasis, Tribals, Indigenous and uncontacted people etc. In India, we mostly refer them as Adivasis/Girijans. Tribal communities are facing number of problems they are educationally backward, deals with many social \& religious issues and faces poverty, exploitation, forced displacement, various health problems and many more.

Like other societies, tribal society is also not static, rather is quite dynamic. The transformation among tribal society is very slow. That is why they have been backward and poor in comparison to other communities. Since they have been materially backward and economically poor, attempts have been made by the Government to develop them. Today, the governments of all over the world are paying special attention towards the development of the tribal.

Corresponding Author:-Purshottam.

Address:-PhD Research Scholar, Department of Social Work, Kurukshetra University, Kurukshetra, 
Number of inclusive policies and programmes are being run by the governments to connect tribals with mainstream of the world.

\section{Objective of The Paper:-}

The main objective of the paper is to understand tribal life and the major problems $\&$ issues being faced by tribes in India. The paper also concentrates on the distribution of tribes in India. The researcher has also given some suggestions for the betterment of tribal community.

\section{Defining A Tribe:-}

The term, "tribe" originated around the time of the Greek city-states and the early formation of the Roman Empire. The Latin term, "tribus" has since been transformed to mean, "A group of persons forming a community and claiming descent from a common ancestor". The Imperial Gazetteer of India, 1911, defines a tribe as a "collection of families bearing a common name, speaking a common dialect, occupying or professing to occupy a common territory and is not usually endogamous though originally it might have been so".

Another definition of a tribe by D.N. Majumdar $(1961,367)$ is that "a tribe is a collection of families or group of families bearing a common name, members of which occupy the same territory, speak the same language and observe certain taboos regarding marriage, profession or occupation and have developed a well-assessed system of reciprocity and mutuality of obligations".

In Indian context the term tribe has never been defined satisfactorily. Tribals in India were considered to be as "backward class" and until 1919 they were termed as "depressed class". The census of India accorded the different nomenclature for tribals, in 1931 census referred them as "primitive tribes", 1941 census as "tribes" and 1951 census as "scheduled tribes". The Constitution of India refers to such communities as 'Schedule Tribes'. In Hindi, the synonyms used for 'Scheduled Tribes' is 'AnusuchitJanjati' and other words like Adivasi, Vanavasi or Adimjati are used as synonyms of tribal.

Article 366 (25) defined scheduled tribes as "such tribes or tribal communities or parts of or groups within such tribes or tribal communities as are deemed under Article 342 to be Scheduled Tribes for the purposes of this constitution". Article 342 prescribes procedure to be followed in the matter of specification of scheduled tribes. The criterion followed for specification of a community, as scheduled tribes are indications of primitive traits, distinctive culture, geographical isolation, shyness of contact with the community at large, and backwardness. This criterion is not spelt out in the Constitution but has become well established.

\section{Tribes of India:-}

India is characterized by having second largest tribal population in the world after Africa and it is interesting to note that there are around seven hundred tribes inhabited all over India.

According the 2011 census, tribals constitute $8.61 \%$ of the total population of the country. The largest concentrations of indigenous peoples are found in the seven states of north-east India, and the so-called "central tribal belt" stretching from Rajasthan to West Bengal. More than half the Scheduled Tribes population is concentrated in the States of Madhya Pradesh, Chhattisgarh, Maharashtra, Odisha, Jharkhand and Gujarat. There are over 700 Scheduled Tribes notified under Article 342 of the Constitution of India, spread over different States and Union Territories of the country. Many tribes are present in more than one state. The largest numbers of scheduled tribes are in the states of Orissa (i.e. 62). Some of the major tribal groups in India include Gonds, Santhals, Khasis, Angamis, Bhils, Bhutias and Great Andamanese. All these tribal people have their own culture, tradition, language and lifestyle. There are many more such tribes in the country, who are living away from the mainstream of the country. There are, however, many more ethnic groups that would qualify for Scheduled Tribe status but which are not officially recognized.

\section{Distribution of Tribes in India:-}

The Scheduled Tribes are notified in 31 States/UTs. The tribal population of the country, as per 2011 census, is 10.43 crore, constituting $8.61 \%$ of the total population. $89.97 \%$ of them live in rural areas and $10.03 \%$ in urban areas. The decadal population growth of the tribal's from Census 2001 to 2011 has been $23.66 \%$ against the $17.69 \%$ of the entire population. 
Figure: State-wise distribution of STs (as per the 2011 census)

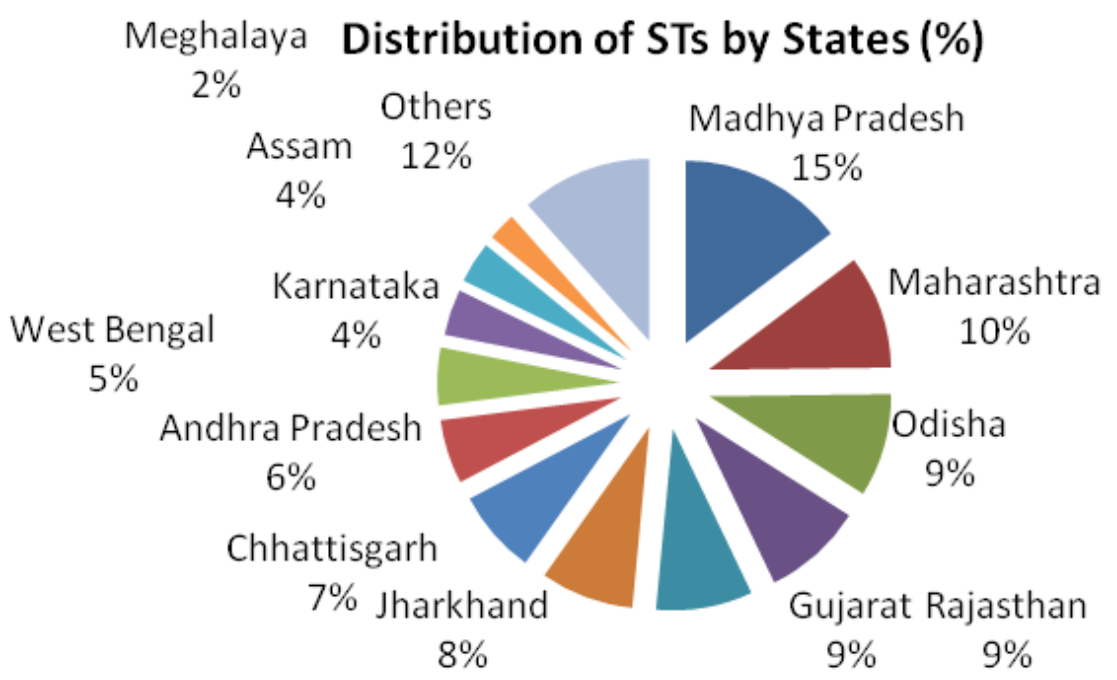

Source:- report of ministry of tribal affairs, 2014.

Meghalaya, Mizoram and Nagaland are the 3 states of India where $100 \%$ of tribal population living in tribal areas. We have $32 \%$ tribal area in India. The sex ratio for the overall population of India is 940 females per 1000 males and that of Scheduled Tribes 990 females per thousand males. At the district level, 2011 Census reveals that there are 90 districts where ST population is 50 per cent or more. As per Census 2001, this number was 75 districts. Out of these 90 districts, 48 districts are in 8 North Eastern States. All the districts in Mizoram, Meghalaya and Nagaland have more than $60 \%$ of ST Population. Madhya Pradesh has the largest number of ST's contributing $14.69 \%$ to the total percentage of ST population of India.

Among States Mizoram (94.43) has highest proportion of STs and Uttar Pradesh the lowest (0.57). Among UTs, Lakshadweep with 94.8 percent of ST Population ranks first and Daman \& Diu has the lowest proportion of STs (6.32). With respect to districts, KurungKumey district of Arunachal Pradesh has the highest proportion of Scheduled Tribes (98.58) and Kannauj in Uttar Pradesh has the lowest proportion of Scheduled Tribes (0.0009). No community has been specified as Scheduled Tribe in relation to the State of Haryana and Punjab and Union Territories of Chandigarh, Delhi and Pondicherry.

\section{History of Tribes In India:-}

India rightly has been described as a 'melting pot' of races and tribes. The ancient and epic literatures, the Vedas, the Puranas, the Ramayana and the Mahabharata emphasize that India is inhabited by several types of tribes or people. The Ramayana tells us about some tribal people. Rakshasas and vanaras, both were being the aboriginal tribes of Deccan. The Rakshasas are regarded by Vyas as the earliest inhabitants of southern India and Shri Lanka. The vanaras are also regarded as the non - Aryan hill tribes of southern India. Their chiefs were Bali and Sugriva. The Nishadas chief, Guha, helped Ram to cross the Ganga. The Mahabharata also mentions a few tribes, Kirata had been used for the non- Aryan tribe mentioned in Mahabharata. Kaurava army mentions the Mundas. Those were known as aboriginal people. Eklavya, a bhil, has gone down in legends as an ideal disciple. Munda and Nagas fought on the side of the Kurus, Bhima's son, Ghatotkacha, who performed prodigies of valour in that war was born of a tribal wife and Arjuna had married a Naga princess.

\section{Major Issues of Tribes of India:-}

As scheduled tribes are indications of primitive traits, distinctive culture, geographical isolation, shyness of contact with the community at large, and backwardness. Therefore, they are facing many problems in their life span. They deal with number of social, religious, educational, health related problems and many more.

\section{Educational Issues:-}

* The Literacy Rate (LR) increased from 8.53 percent in 1961 to 58.96 percent in 2011 for Scheduled Tribes (STs), while the corresponding increase of the total population was from 28.30 percent in 1961 to 72.99 percent 
in 2011. LR increased by 11.86 percentage points from 2001 to 2011 for STs and 8.15 percentage points for total population during the same period.

* Currently, SarvaShikshaAbhiyan (SSA) is implemented as India's main programme for universalizing elementary education. The new law provides a justifiable legal framework that entitles all children between the ages of 6-14 years free and compulsory admission, attendance and completion of elementary education. It provides for children's right to an education of equitable quality, based on principles of equity and nondiscrimination.

* There are still a large number of schools which do not have minimum facilities.

- The Annual Status of Education Report (ASER), covering 550 tribal rural districts, reveals that 93 per cent of students of Class V were unable to read Class II textbook contents in 2013 whereas, in 2005, it was 97 percent.

* Literacy rate of STs are $58.96 \%$, SCs are $66.07 \%$ and all social groups are $72.99 \%$. Still there is huge gap which is matter of serious concern.

* Dropout rates among the tribal students, particularly at the secondary and senior secondary stages, are very high. With dropout rates of 73 per cent at Class X, 84 per cent at Class XI and 86 per cent at Class XII, higher education also suffers.

* In a recent report, Human Rights Watch records that the Principal of one of school of Sonbhadra District in Uttar Pradesh stated that the tribal children were a 'big problem' in the school. Such prejudice not only precludes the potential for tribal children learning in the classroom, it also perpetuates discrimination and exclusion.

* There are many reasons for low level of education among the tribal people. Formal education is not considered necessary to discharge their social obligations. Superstitions and myths play an important role in rejecting education. Most tribes live in extreme poverty. It is not easy for them to send their children to schools, as they are considered extra helping hands. The formal schools do not hold any special interest for the children. Most of the tribes are located in interior and remote areas where teachers would not like to go from outside.

* Nomadic tribes are constantly mobile depending on the climate, occupations and livelihood opportunities, providing education to these tribes is not an easy task.

\section{Religious Issues:-}

$>$ Tribal people belief in the existence of super human or supernatural power, such kind of beliefs and worship created many questions in the mind of young educated people.

$>$ Due to contact with other cultures, the tribal culture is undergoing a revolutionary change. The tribal people are imitating western culture in different aspects of their social life and leaving their own culture. It has led to degeneration of tribal life and tribal arts such as dance, music and different types of craft.

\section{Social Issues:-}

$>$ Child marriage among tribes still exists in the states like Bihar and Andhra Pradesh, which is constitutionally wrong and many demerits are attached with such practices.

$>$ Polyandry and polygamy exits in some tribes of Himalayas. Such practices are not really acceptable in this modern world.

$>$ Infanticide, homicide, animal sacrifice, black magic, exchange of wives and other harmful practices are still found among tribes.

$>$ Language is also one of the barriers for the promotion of education among tribes.

\section{Health issues:-}

$>$ There are wide variations with regard to health education status, access and utilization of health services among the tribal populations. Public Health Serviceto Scheduled Tribe population is one of the weakest links.

$>$ The major difficulty in delivering public health care to tribal population is the lack of health care human resource that is willing, trained and equipped to work in Scheduled Areas. There is a shortage, vacancy, absenteeism or half-heartedness of doctors, nurses, technicians and managers in public health care system in Scheduled Areas.

$>$ A reason for the inappropriately designed and poorly managed health care in Scheduled Areas is the near complete absence of participationof Scheduled Tribes people or their representatives in shaping policies, making plans or implementing services in the health sector.

$>$ Coverage with medical insurance including the Rashtriya Swasthya Bima Yojana (RSBY) remains extremely low in the Scheduled Areas. Thus the Scheduled Tribes populations are almost completely without financial protection against acute and catastrophic illnesses. 
> Consumption of Tobacco and Alcohol: Data on Xaxa Committee Report 2014 shows high consumption of tobacco, both through smoking or chewing among men in the age group of 15-54 years. The prevalence of tobacco consumption was around 72 and 56 percent among Scheduled Tribes and Non-Scheduled Tribes respectively. Consumption of alcohol is a part of social rituals in many tribal communities. At the national level, it is noted that about half of Scheduled Tribe men (51 percent) consume some form of alcohol. Around 73 percent rural Scheduled Tribe men consumed tobacco as compared to 60 percent among urban counterparts.

$>$ The prevalence of tobacco consumption among Scheduled Tribe men was quite high in states like West Bengal, Bihar, Mizoram and Odisha (more than 80 percent). This also promotes serious health problems.

$>$ Open defecation among schedule tribes is also very high, which is a matter of great concern. About 75 percent of Scheduled Tribe households reported defecating in the open. The proportion is much higher in rural areas for Scheduled Tribes ( 82 percent) as compared to urban areas (26 percent). The situation is deplorable when we observe the state level data, where Scheduled Tribe households are at greater disadvantage in states like Rajasthan, Odisha, Jharkhand and Madhya Pradesh as they have lesser access to improved sanitary facilities and mostly resorted to open defecation. These states account for more than 50 percent of tribal population.

$>$ Total fertility rate and the mortality indicatorsof Scheduled Tribe population have certainly improved during the past decades. However, these are significantly worse than of the general population. The 1-4 year mortality is 33.6 in Scheduled Tribes and 10.3 in the non-Scheduled Tribes.

> Infant Mortality Rate (IMR) in the Scheduled Tribes population is about 62 per 1000 live births and Under Five Mortality Rate (U5MR) is 96 per 1000 live births. Compared to rest of the population, IMR was higher by 27 percent and U5MR rate was higher by 61 percent. The 1-4 year mortality is 33.6 in Scheduled Tribes and 10.3 in the non-Scheduled Tribes. In Scheduled Tribes population, there was only about 10 percent reduction in the Infant Mortality Rate (IMR) during 1992-98, whereas in the total population about 25 percent reduction occurred during the same period.

$>$ Census 2011 of India shows that just about 11 percent of tribal households in the country have access to tap water and only three percent households have tap water from treated source.

$>$ The nutritional statusof Scheduled Tribe children as well as of adults reveals a sad picture.

\section{Other Related Issues:-}

Land Alienation, Displacement and Enforced Migration of tribes in India is also one of serious issues they deal with.

$>$ Land Alienation: The history of land alienation among the tribes began during British colonialism in India when the British interfered in the tribal region for the purpose of exploiting the tribal natural resources. This brought increasing destitution and displacement. After the British came to power, the Forest policy of the British Government was more inclined towards commercial considerations rather than human.

$>$ Theexpansion of railway in India heavily devastated the forest resources in India. Forest land and its resources provide the best means of livelihood for the tribal people and many tribes including the women engage in agriculture, food gathering and hunting they are heavily dependent on the products of the forest. Therefore when outsiders exploit the tribe's land and its resources the natural life cycle of tribal ecology and tribal life is greatly disturbed.

> Migration: Tribal people suffer predominantly from the phenomenon of poverty-induced migration on account of rain-fed agriculture and absence of other avenues of employment. Fragmentation of land, loss of land due to acquisition and illegal land alienation by non-tribals also cause people to migrate.

$>$ Deforestation and decreasing access to forests and drought are other contributory factors for tribal migration. It is estimated that, in the last decade, about 3.5 million tribal people are leaving agriculture and agriculturerelated activities to enter the informal labour market.

$>$ Tribal people faced with influx of immigrants, fear loss of identity, land, destruction of forests, jobs and losing political control.

$>$ Process of involuntary displacement on the name of development is also burning issue among tribes of India. Mineral and hydro-electric resource-rich places are home to vast majority of tribal people. Displacement is a process in which marginalized sections, the majority being tribal people, are pushed out of their own habitat and dispossessed of their resources and indeed their universe around them.

$>$ The unrestricted power of the State to acquire privately-owned land without any obligation on the State resulted in large number of cases of inadequate compensation, forcible acquisition even without payment of compensation, without replacement of livelihood, without provision of alternative land, without preparation of 
resettlement sites and without recognition of loss of right to access forest, and loss of community ties, cultural and religious heritage.

$>$ In mining projects, resettlement sites are situated close to mining operations, which result in respiratory diseases. Ill-health causes them to spend most of their earnings towards allopathic medical treatment, due to non-availability of herbal medicines.

$>$ Of the estimated 60 million Displaced/Project Affected Peoples, about 40 per cent are tribal people, 20 per cent are Scheduled Caste and 20 per cent belong to other social groups, like OBCs. It is also estimated that only 25 per cent of all DPs have been resettled and only 21.16 per cent tribal DPs have been resettled, which is a worst situation.

$>$ Poverty and Indebtedness: Majority tribes live under poverty line. The tribes follow many simple occupations based on simple technology. Most of the occupation falls into the primary occupations such as hunting, gathering, and agriculture. The technology they use for these purposes belong to the most primitive kind. There is no profit and surplus making in such economy. Hence there per capita income is very meager much lesser than the Indian average. Most of them live under abject poverty and are in debt in the hands of local moneylenders and Zamindars. In order to repay the debt they often mortgage or sell their land to the moneylenders. Indebtedness is almost inevitable since heavy interest is to be paid to these moneylenders.

$>$ Exploitation and Unrest of the tribes: For ages tribals are considered primitive segment of Indian society. They lived in forests and hills without any contact with civilizations. Many non-tribals began to settle in the tribal areas because the British introduced the system of landownership and revenue. Annual tax was trebled which was beyond the paying capacity of tribal cultivators. Non tribals offering credit facilities to tribals. Initially it provided relief to tribals but gradually the system became exploitative. Over the years the tribal population faced all types of exploitation. This aroused the tribal leaders to mobilize the tribals and start agitations.

$>$ According to Crime in India- 2015, a total of 6,275 cases of atrocities against person belonging to Scheduled Tribe (in which SC/ST(POA) Act applied) were registered in the country during 2015, showing a decrease of $8.1 \%$ (from 6,826 cases in 2014 to 6,375 cases in 2015) during 2015 over 2014. The highest incidents of atrocities against STs were reported from Rajasthan (1,409 cases) followed by Madhya Pradesh (1,358 cases) during 2015. The highest rate of atrocities against STs was reported from Kerala (34.0) followed by Rajasthan (15.3), Andhra Pradesh (13.8), Telangana (11.7) and A \& N Island (10.5) compared to 6.0 at all India level during 2015.

$>$ Tribal women and children continue to suffer from various forms of violence, including killing, rape and torture by non-tribals.

$>$ The 5th Schedule and 6th Schedule to the Constitution of India provide stringent protection of the land belonging to the tribal peoples. In addition, at the state level, there is a plethora of laws prohibiting the sale or transfer of tribal lands to non-tribals and the restoration of alienated tribal lands to them. However, the laws are either not properly implemented or they are manipulated to facilitate the transfer of tribal lands to non-tribals.

$>$ Only $17.3 \%$ of STs are living in households having bathing facility within the premises.

$>87.50 \%$ STs are using firewood/ coal/ charcoal for cooking inside the house.

$>$ Large numbers of tribals, men and women, are in jails for what are termed 'naxal offences'. Most of them would be innocent.

So these are numerous issues tribals dealing with, which should be taken into consideration.

\section{Suggestions:-}

On the basis of literature and observations, the researchers have given following suggestions as follows:-

$>$ Inclusion of local culture, folklore and history in the curriculum can help in building confidence of tribal children and enhance the relevance of education in their lives. Music and dance are a central part of tribal life. Therefore, storytelling, theatre, painting, music and dance performances should be promoted. It may help in increment of literacy rate of tribes of India.

$>$ Similarly, sports such as football, archery and other popular local sports are extremely beneficial and therapeutic for children, and should be promoted.

$>$ Outdated tribal policies and programmes should be terminated or revised.

$>$ A tribal community needs a special health plan. Such a 'Health Plan' should be constructed on the basis of needs of tribal peoples. Focus should be given on the delivery of health services in tribal areas, which is very poor. This 'Tribal Health Plan' should become an essential feature of the National Health Mission and of the Tribal Sub Plan. 
$>$ There is a dire need to establish agro-based training institutions and related labour-intensive processing industries in tribal regions. In order to make use of land available with the tribal farmers, they should be motivated to undertake organic farming and eco-forestry. This requires concerted efforts by the Departments of Agriculture and Forest to motivate the tribal farmers to undertake such activities.

$>$ Data on development parameters with respect to STs are not available for the purpose of policy planning and implementation. Therefore, a National Institute of Tribal Development, an autonomous research organization, has to be set up exclusively for undertaking research on STs.

$>$ Tribals should be encouraged to use their traditional knowledge to meet their needs by recreating their forest ecosystem and forest-based livelihood. Although majority of STs have land and cultivation is their main occupation.

$>$ Water for agriculture is the greatest impediment in production. Micro watershed development program with people-centered participatory approach is a good method for poverty reduction through natural resource management in tribal regions. Therefore, micro watershed should be given top-most priority in tribal areas to enhance agricultural productivity.

$>$ Tribal friendly development policies and programmes should be initiated.

$>$ Lack of Awareness is the main reason of poor health and backwardness of tribes. Awareness programmes for sanitation, health and hygiene and for information of the government special programmes for STs should be promoted.

\section{Conclusion:-}

Tribals are among the most deprived and oppressed sections of India. Half of the adivasi people do not have land. Poverty, deprivation and now the reduction of government expenditure on basic medical health facilities is reflected the absolutely poor health condition of adivasi women and children. India has several laws and constitutional provisions, such as the Fifth Schedule for mainland India and the Sixth Schedule for certain areas of north-east India, which recognize indigenous peoples' rights to land and self-governance. The laws aimed at protecting indigenous peoples have, however, numerous shortcomings and their implementation is far from satisfactory.

After discussing the number of issues of tribes of India, we are still hoping for the best results in future as we are in the era of development. Development process is slow but not static. The constitution of India has many articles and provisions, which favours the development and welfare of tribes, and there are number of examples which show the relevance of these provisions. We have poor links of health, education \& employment in tribal areas due to harsh geographical conditions. The government has started many development schemes for scheduled tribes such as; Tribal Sub Plan, extra tribal allowances for employees in tribal areas, health cards for BPL families, post metric scholarship programme, Rajeev Gandhi fellowship for higher education and many more, which will definitely help the tribes to deal with above discussed issues.

\section{References:-}

\section{Books and Research papers:-}

1. Bajpai, S. C. (2000). Lahaul- Spiti: A Forbidden Land in the Himalayas. New Delhi: Indus Publishing Company.

2. Bhati, J.P., Singh, R., \& Sharma, L. (1998). Income and employment opportunities in tribal areas of Himachal Pradesh: Present status and challenges for Development. New Delhi: Indus Publishing Company.

3. Halavath, K. (2014). Human Rights and Realities of Tribals' Lives in India: A Perfect Storm. IOSR Journal of Humanities And Social Science, 19 (4), 43-46.

4. Hunter, W. W., \& Hunter, S. W. W. (2011). The Imperial Gazetteer of India, Volume IV. London: British Library, Historical Print Editions.

5. Joshi, V. (1998). Tribal Situation in India: issues in development. New Delhi: Rawat Publications.

6. Khan,Y. A. (2000). Tribal life in India. Jaipur, SMS Highway: RBSA Publications.

7. Majumdar, D. N. (1961). Races and Cultures of India. Bombay: Asia Publishing House.

8. Mishra, A., \&Sarma, S. (2011). Understanding Health and Illness among tribal communities in Orissa. Indian Anthropologist, Vol.41, No. 1, 1-16.

9. Singh, A. K. (2008). Tribal Development in India. New Delhi: Serials Publications.

10. Soundarapandian, M. (2001). Tribal Development in India. New Delhi: Anmol Publications Pvt.Ltd.

11. Thakur, D. (1986). Socio- Economic Development of Tribes in India. New Delhi: Deep \& Deep Publications.

12. Verma, V. (2012). Lahaul: A Tribal Habitat in Himachal Pradesh. Delhi: B.R. Publishing Corporation. 
13. Vidyarthi, L. P., \& Rai, B. K. (1985). The Tribal culture of India. New Delhi: Concept Publishing Company. 14. Vidyarthi, L.P. (1981). Tribal Development and its Administration. New Delhi: Concept Publishing Company.

15. Xaxa, V. (1999). Transformation of Tribes in India: Terms of Discourse. Economic and Political Weekly, 15191524.

\section{Reports:-}

1. Annual Status of Education Report, $(2005,2013)$.

2. Census of India, 2011.

3. Crime in India Report, 2015.

4. The Constitution of India, Government of India, Article 342.

5. Ministry of Tribal Affairs Government of India. (2014). Report of the high level committee on socio-economic, health and educational status of tribal communities of India. Retrieved from http://www.kractivist.org/wpcontest/uploads/2014/12/trival-committee-report-may-june-2014.pdf.

6. National Commission for Scheduled Tribes. (2007). A Handbook. Retrieved from http://www.aicteindia.org/downloads/handbook\%20for\%20Scheduled\%20Tribes.pdf

7. Report of the High Level Committee on Socio, Economic, Health and Educational Status of Tribal Communities in India. (2014). Ministry of Tribal Affairs, Govt. of India.

8. Statistical Profile of Scheduled Tribes in India. (2013). Report of Ministry of Tribal Affaires, Statistical Division.

9. Study analysis of the Union Budget: 2016-17, The Dalit Adivasi Perspective, NCDHR, New Delhi, available at http://www.ncdhr.org.in/Dalitsinnews/Final_Budget_Watch_2016-17_Union.pdf

10. Xaxa Committee Report 2014, p 206

\section{Internet:-}

1. Indigenous Peoples. (n.d.). Retrieved May 6, 2017, from https://en.wikipedia.org/wiki/Indigenous_peoples

2. Exploitation and Unrest of the tribes. (n.d.). Retrieved May 6, 2017, from http://www.sociologyguide.com/tribal-society/exploitation-and-unrest.php

3. Tribes of Himachal Pradesh. (n.d.). Retrieved June 29, 2017, from http://www.indianetzone.com/10/tribes_himachal_pradesh.htm

4. The Uncontacted Indians of Brazil. (n.d.). Retrieved July 6, 2017, from http://www.survivalinternational.org/tribes/uncontacted-brazil 